\title{
Thermal Study for Power Uprating of 400 MW Generator Using Numerical Simulation
}

\author{
Hilman Syaeful Alam, Imam Djunaedi, and Demi Soetraprawata
}

\begin{abstract}
One way to get more power out of the generator in a power plant is by implement a power uprating, however it is required design review especially for thermal characteristic of generator in order to prevent over heat and heat concentration point which can lead to the failure of insulation systems. In this study, thermal characteristics of $400 \mathrm{MW}$ Generator due to power uprating had been analyzed using numerical simulation based on finite element. Case study was conducted on the generator of SURALAYA Coal Fired Power Plant in Indonesia based on the three conditions, i.e. existing condition, $5 \%$ and 7\% uprating. Based on simulation results, the temperature distribution in the generator was able to be represented in detail in every segment where there was no indication of heat concentration point or hotspot on the generator. The increasing temperatures on winding due to the $5 \%$ and $7 \%$ uprating were respectively $29.9^{\circ} \mathrm{C}$ and $31.1{ }^{\circ} \mathrm{C}$ by the largest error $\pm 3.33 \%$.
\end{abstract}

Index Terms-Power output, temperature, stress, generator insulation.

\section{INTRODUCTION}

One of the considerations in many power plants is how they get more power out of their existing equipment. In many cases, some equipment may be capable of a $5 \%$ increase in power output or uprating, because the margin already exists [1]. For generators, one way to uprating is to the make full use of any margin that exists to raise the field current and thereby increase the power output, but the consequences will raise the temperature and stress on probably all of the generator components, and primarily on the copper winding and insulations. According to Azizi et al. [2], the troubles initiated in the insulation are one of the primary root causes of failures of electric machines because one-third of the forced outages of large generators in generating stations and industrial plants are the caused by the failure of insulation systems. In some cases, most of generators may be able to handle the increasing temperature by modifying the cooling system. For large generator with a cooling system using hydrogen, the modification can be done by increasing the hydrogen pressure inside the machine, but the method is limited by the strength of other components for example

Manuscript received May 19, 2015; revised January 10, 2016. This work was motivated by a memorandum of understanding $(\mathrm{MoU})$ which has been implemented by the Indonesian Institute of Sciences (LIPI) and PT. Indonesia Power in the fields of research and development of electricity on November 7, 2011 with the MoU Number: 8.MOU/2/IP/2011 and 10/KS/LIPI/IX/2011.

Hilman Syaeful Alam and Demi Soetraprawata are with the Technical Implementation Unit for Instrumentation Development, Indonesian Institute of Sciences, Jl. Sangkuriang Komp. LIPI Gd. 30, Bandung, 40135, Indonesia (e-mail: hilm003@lipi.go.id, demistp@gmail.com)

Imam Djunaedi is with the Research Center of Physics, Indonesian Institute of Sciences, Jl. Sangkuriang Komp. LIPI Gd. 80, Bandung, 40135, Indonesia (e-mail: imam_djunaedi@yahoo.com). casings or hydrogen seals [3]. Therefore, thermal analysis is needed to determine the effect on the increasing of hydrogen pressure in the cooling system. In addition, temperature distribution analysis is highly necessary to ensure there is no heat concentration point or hotspot that might cause damage to the insulation on the winding or demagnetization.

Since the ability and speed of modern computers has increased rapidly and allows to run the calculations in a relatively short time, the thermal analysis of electric machines has become an interesting research field for both industry and investigators to improve the cooling performance and to enhance the efficiency of electric machine. In order to predict precisely the thermal characteristics of electric machines, thermal analysis can be divided into two methods: Lumped Parameter Thermal Model (LPTM) and numerical method. The LPTM is the main tool for a fast yet accurate thermal analysis. However, a common drawback to this approach can make it useless to a designer, because there is a need for experimental data in order to tune parameters that are very important in order to obtain accurate results [4]. It is of common practice in thermal modeling of electric machine to use the lumped thermal method, however if higher level of detail is required, it needs to use the more refined methods like numerical method based on finite element or finite difference. These types of methods can give a highly accurate and clear view of the temperature distribution within the electric machine [5]. Based on these advantages, numerical method has been applied to assist in analyzing the thermal characteristics of some electric machine: micro gas turbine generator [6], switched reluctance generator [7], large ring motor for mining industry [8], Permanent magnet generator for large direct-drive wind turbines [9], and axial-flux permanent magnet generator [10].

This paper considers the thermal analysis on a $400 \mathrm{MW}$ hydrogen cooled generator using numerical method based on finite element. The study was conducted on the generator in SURALAYA Coal Fired Power Plant, in Indonesia as one of the important aspects required in the planning for uprating or increasing the power output of generator. Thermal analysis is focused to determine its influence on the increasing of hydrogen pressure in the generator cooling system. In addition, the temperature distribution on the generator was studied to ensure there is no heat concentration point or hotspot that might cause damage to the insulation or demagnetization.

\section{MATERIALS AND METHODS}

\section{A. Generator Main Characteristics}

Generator Unit 3 in Suralaya Power Plant is a Hydrogen 
Cooled, 3-phase synchronous Generator, 23kV, 0.85PF, 3 phase, 50 hertz, $3000 \mathrm{rpm}$ with manufacturing year in 1987. The main characteristics of generator are shown in Table I.

TABLE I: MAIN CHARACTERISTICS OF GENERATOR

\begin{tabular}{llll}
\hline Parameter & Sym. & Value & Unit \\
\hline Power & $P$ & 400.350 & $M W$ \\
Nominal Voltage & $E$ & 23000 & $V$ \\
Nonimal Frequency & $f$ & 50 & $\mathrm{~Hz}$ \\
Number of Phase & $m$ & 3 & \\
Nominal Speed & $n$ & 3000 & $\mathrm{rpm}$ \\
Pole Number & $p$ & 2 & \\
Hydrogen Cooled Pressure & $\mathrm{Hpr}$ & 3.10 & $\mathrm{bar}$ \\
Stator Outer Diameter & $D_{o}$ & 2.784 & $\mathrm{~m}$ \\
Stator Inner Diameter & $D_{i}$ & 1.328 & $\mathrm{~m}$ \\
Rotor Outer Diameter & $D_{r}$ & 1.014 & $\mathrm{~m}$ \\
Number of Slot Stator & $S_{s}$ & 30 & \\
Sinusoidal Flux density & $B_{p}$ & 1.7 & Tesla \\
Winding Resistance per Phase & $R_{a}$ & 0.00127 & Ohm \\
Phase Current & $I$ & 11823 & $\mathrm{~A}$ \\
Weight of the rotor & Wr & 60200 & $\mathrm{~kg}$ \\
Length of stator lamination & Len & 6.002 & $\mathrm{~m}$ \\
Coil Width of stator & bs & 0.063 & $\mathrm{~m}$ \\
Coil Height of stator & hs & 0.12 & $\mathrm{~m}$ \\
\hline
\end{tabular}

\section{B. Losses Calculations}

According to Ohyama et al. [11], heat in generator is produced by total losses which comes from copper or winding losses $\left(P_{c u}\right)$, core losses $\left(P_{\text {core }}\right)$ and rotational losses $\left(P_{r o t}\right)$. Those losses are then dissipated to all parts of the machine. At the generator, winding/copper losses, $P_{c u}$ are generated due to resistances of the coil or winding that generates heat effects as the conversion of electric energy. Winding losses can be mentioned using the following equation [12]:

$$
P_{c u}=m R_{a} I^{2}
$$

where $m=$ phase number, $R_{a}=$ winding resistance per phase $(\Omega)$, and $I=$ phase current (A).

Core losses, $P_{\text {core }}$ are the sum of hysteresis loss and eddy current loss. Core losses can be represented by the following equation [11]:

$$
P_{\text {core }}=C_{h} f B_{p}{ }^{a+b B_{p}}+C_{e} f^{2} B_{p}{ }^{2}
$$

where $C_{h}=$ coefficient of hysteresis loss $=0.025, C_{e}=$ coefficient of eddy current loss $=7.9365 \mathrm{e}-5, a$ and $b$ are constants which depend on the stator material (for soft magnetic/silicon steel, $a=1.8317$ and $b=-0.0035)$. $f=$ frequency, and $B_{p}$ is sinusoidal peak of the flux density. Rotational losses $P_{\text {rot }}$ consist of friction and windage losses, the rotational losses can be calculated using the following equation [11]:

$$
P_{r o t}=P_{\text {fric }}+P_{\text {wind }}
$$

Friction loss is computed using equation:

$$
P_{f r i c}=k_{f b} W_{r} n \cdot 10^{-3}
$$

where $k_{f b}$ is the constant of bearing friction with the approximation of $1-3, W_{r}=$ weight of the rotor $(\mathrm{kg})$ and $n=$ rotational velocity (rpm). Meanwhile, wind losses $P_{\text {wind }}$ are computed using equation:

$$
P_{\text {wind }}=2 D_{r}^{3} L_{e n} x 10^{-6}
$$

where $D_{r}=$ outer diameter of the rotor $(\mathrm{m})$ dan $L_{e n}=$ length of stator lamination $(\mathrm{m})$.

\section{Heat Transfer Mechanism}

The source of heat in generator is dissipated to all parts of the machine following the pattern of radial heat flow or in the same direction as the generator radial axis and circumpherential heat flow or upright to the generator radial axis as shown in Fig. 1. For a 2-D thermal analysis, axial heat flow which goes towards the same direction as the axis of generator shaft can be neglected.

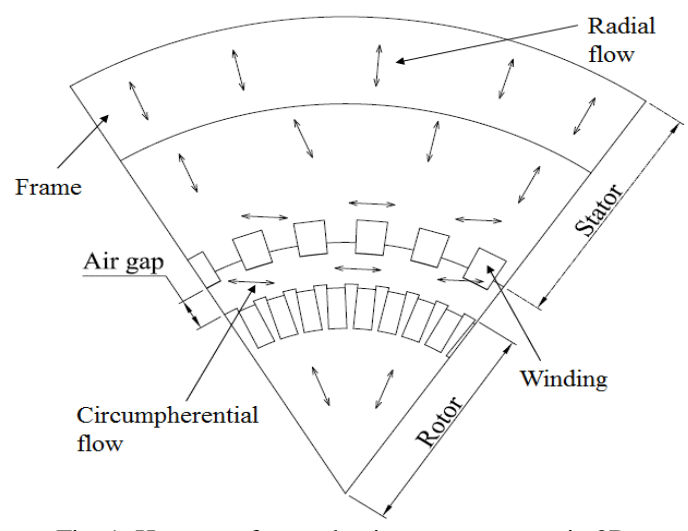

Fig. 1. Heat transfer mechanism on generator in 2D.

In general the equation for heat transfer is based on the principle of energy conservation postulating that the network generated equals to the sum of heat produced and energy alteration stored in the system. Mathematically it can be written as follows [13]:

$$
\bar{\nabla} q=Q-\frac{\partial e}{\partial t}
$$

where $q$ is the heat conduction, $Q$ is the heat generated in the system, $\delta e / \delta t$ the change in internal energy. $q$ is derived from Fourier law as heat conduction, namely:

$$
q=-k \bar{\nabla} T
$$

Therefore, heat transfer on a solid material can be stated in a partial differential equation as follows [13]:

$$
\bar{\nabla}(k \bar{\nabla} T)+Q-\rho C_{p} \frac{\partial T}{\partial t}=0
$$

where $k$ is thermal conductivity, $C_{p}$ is specific heat capacity, $\rho$ is density, $Q$ is rate of the heat which is generated per volume, and $T$ is distribution of the predetermined temperature.

In addition to conduction, heat can be transferred through convection and radiation. Computation of convection heat transfer is more complicated due to involvement of fluid movement and conductive heat. Newton gives a theory that heat transfer that passing thru a certain area is in accordance with the temperature difference of solid fluid. Temperature difference normally occurs through fluid borders located close to the solid surface. The Newton equation can be stated as follows [13]-[15]:

$$
Q_{c}=h_{c} A\left(T-T_{A}\right)
$$


where $h_{c}$ is coefficient of the convection heat transfer, $A$ is area of the heat transfer, and $T_{A}$ is room temperature.

For natural convection, coefficient of the convection from the air is approximately between $6-30 \mathrm{~W} / \mathrm{m}^{2}{ }^{\circ} \mathrm{C}$ and for force convection, it is around $30-300 \mathrm{~W} / \mathrm{m}^{2}{ }^{\circ} \mathrm{C}$ [16]. For heat transfer by radiation, it occurs from or to the surface surrounded by parallel air with convection between the air and surface. Therefore, the total heat transfer is determined by adding the contribution of those two heat transfer mechanisms. Heat transfer by radiation can be computed using following equation [13]-[15]:

$$
Q_{r}=\varepsilon \sigma_{t} A\left(T^{4}-T_{A}^{4}\right)
$$

From the equation above, coefficient of the radiation heat transfer, $h_{r}$, can be determined as follows:

$$
h_{r}=\frac{\varepsilon \sigma_{t}\left(T^{4}-T_{A}\right)}{\left(T-T_{A}\right)}
$$

As the result, the total of heat losses in the generator due to convection and radiation, $Q_{c r}$ is as follows:

$$
Q_{c r}=\left(h_{c}+h_{r}\right) A\left(T-T_{A}\right)
$$

During thermal analysis using finite element, heat transfer effects caused by radiation is simply ignored due to the high emissions of copper material and silicon steel inside the stator generator, which respectively are 0.63 and 0.7 [13]. Then, material properties of the generator components associated with thermal analysis can be seen in Table II.

TABLE II: MATERIAL PROPERTIES OF GENERATOR COMPONENTS

\begin{tabular}{llll}
\hline Segment & Material & $\begin{array}{l}\text { Specific Heat } \\
\text { Cap. }\left(\mathrm{MJ} / \mathrm{m}^{3} \mathrm{~K}\right)\end{array}$ & $\begin{array}{l}\text { Thermal Cond. } \\
(\mathrm{W} / \mathrm{mK})\end{array}$ \\
\hline Stator & Silicon Steel & 3.77 & 30 \\
Winding & Copper & 3.4 & 360 \\
Frame & Al-Alloy & 2.43 & 220 \\
Shaft and rotor & Forged Steel & 3.53 & 52 \\
Ventilation hole & Air & 0.0012 & 0.025 \\
\hline
\end{tabular}

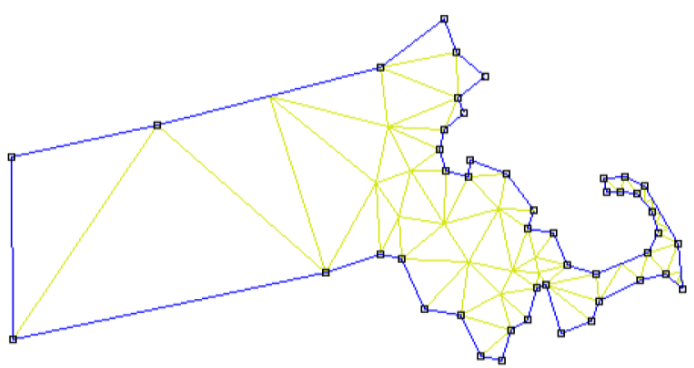

Fig. 2. Discretization of domain using triangular element in FEMM 4.2 [15].

\section{Finite Element Simulation}

Thermal analysis and temperature distribution on the generator is carried out using numerical method based on the finite element (FEM). This method is able to give the approximation of unknown values on some discrete points of a continuum by dividing the continuum into smaller elements interconnected to each other at a certain common point of two or more elements (nodal points or nodes) with limited number (finite element) from a simpler geometry than the previous continuum [18], [19]. In this study, FEMM 4.2 was used as one of FEM software based on open source. Specifically, FEMM 4.2 discretizes the problem domain using triangular elements as shown in Fig. 2.

Over each element, the solution is approximated by a linear interpolation of the values of potential at the three vertices of the triangle. The linear algebra problem is formed by minimizing a measure of the error between the exact differential equation and the approximate differential equation as written in terms of the linear functions. The simulation procedures using FEMM 4.2 consist of geometric modeling, material definition, setting of boundary condition, meshing or discretization and presenting the results. In geometric modelling, geometry of the generator is modelled into a quarter of segment of the 2D-generator, because the other parts of segments are symmetrical. The types of materials is previously defined in Table II are then correlated to the accordingly segments as depicted in material boundary. There are two boundary conditions that are used in simulation. The first is the heat flux as a source of heat generated from the calculation of losses in the generator $\left(P_{r o t}\right.$, $P_{c u}$, and $\left.P_{\text {core }}\right)$ and the second is the convection boundary conditions that are applied to the area or boundaries related to the cooling temperature. The boundary conditions, geometry and material boundary are shown in Fig. 3.

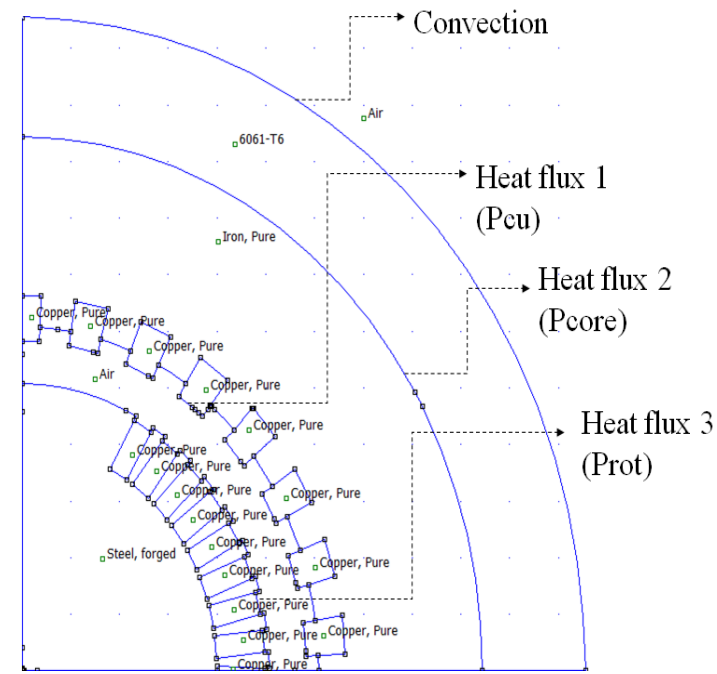

Fig. 3. Geometry and boundary condition.

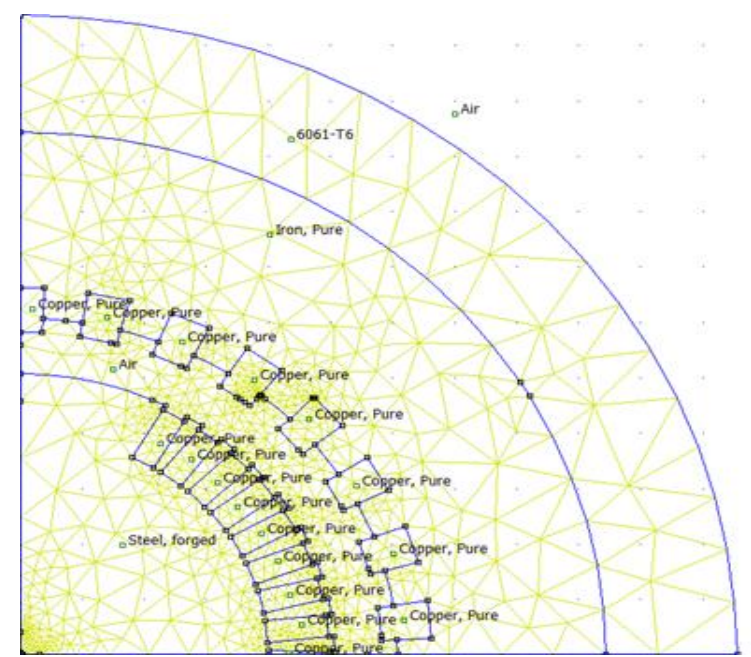

Fig. 4. Result of meshing process.

The next step in simulation is meshing. In meshing, the smaller the element, the more accurate result of simulation will be. The capability in defining the number of elements is greatly influenced by the capability/specification of not only 
the computer but also the software in use. In this study, meshing process establishes 1164 nodes and 2211 elements which are shown in Fig. 4.

\section{E. Heat Removal Calculation}

The cooling of the armature winding is dependent on a number of factors: cooling medium (air, hydrogen, water); insulation thickness; and overall electrical losses. Table III illustrates a relative heat removal capability improves from air to hydrogen, with increased hydrogen pressure, and even more significant with the use of water cooling [20]. In this study, thermal analysis on the generator using finite element simulation based approach using air cooling system. Then the simulation results calculated linearly based on the data of cooling using hydrogen at a predetermined pressure. Finite element simulations performed on the existing condition, $5 \%$ and $7 \%$ uprating, where each condition were analyzed using air cooling systems and hydrogen.

TABLE III: GENERATOR HEAT REMOVAL CAPABILITIES OF VARIOUS FLUIDS [20]

\begin{tabular}{llll}
\hline Fluid & $\begin{array}{l}\text { Relative } \\
\text { specific heat }\end{array}$ & $\begin{array}{l}\text { Relative } \\
\text { density }\end{array}$ & $\begin{array}{l}\text { Approx. rel. heat } \\
\text { removal }\end{array}$ \\
\hline Air & 1.0 & 1.0 & 1.0 \\
Hydrogen 2.07 bar & 14.36 & 0.21 & 3.0 \\
Hydrogen 3.10 bar & 14.36 & 0.26 & 4.0 \\
Water & 4.16 & 1000.0 & 50.0 \\
\hline
\end{tabular}

\section{RESULTS AND DISCUSSION}

The main source of heat in generator is produced from the windings located at stator's lamination, and dissipated to all parts of the machine. By adding the influence of the other losses, the losses calculation results according to eq. (1) to (5) based on existing conditions, $5 \%$ and $7 \%$ uprating can be shown in Table IV. From the calculation results for the all three condition, only winding losses are increased according to the increasing of the current phase. The calculation results of heat flux adjusted to the location of the boundary condition where the area for winding losses, core losses and rotational losses are respectively $65.90 \mathrm{~m}^{2}, 48.25 \mathrm{~m}^{2}, 47.87 \mathrm{~m}^{2}$.

TABLE IV: LOSSES CALCULATION RESULTS FOR EXISTING, 5\% UPRATING AND $7 \%$ UPRATING

\begin{tabular}{|c|c|c|c|}
\hline Looses & $\begin{array}{l}\text { Existing } \\
\text { Cond. }\end{array}$ & $\begin{array}{l}5 \% \\
\text { Uprating }\end{array}$ & $\begin{array}{l}7 \% \\
\text { Uprating }\end{array}$ \\
\hline Winding looses, $\mathrm{kW}$ & 532.57 & 587.16 & 609.74 \\
\hline Core looses, kW & $9.03 \mathrm{E}-04$ & $9.03 \mathrm{E}-04$ & 9.03E-04 \\
\hline Friction Looses, kW & 180.60 & 180.60 & 180.60 \\
\hline Windage Looses, $\mathrm{kW}$ & $2.46 \mathrm{E}-08$ & $2.46 \mathrm{E}-08$ & $2.46 \mathrm{E}-08$ \\
\hline Rotational Looses, $\mathrm{kW}$ & 180.60 & 180.60 & 180.60 \\
\hline Heat flux of wind., W/m $\mathrm{m}^{2}$ & 8081.31 & 8909.65 & 9252.30 \\
\hline Heat flux of core, $\mathrm{W} / \mathrm{m}^{2}$ & 0.02 & 0.02 & 0.02 \\
\hline Heat flux of rot., $\mathrm{W} / \mathrm{m}^{2}$ & 3772.75 & 3772.75 & 3772.75 \\
\hline
\end{tabular}

The results of losses calculation is then used as an input data for finite element simulation. Thermal simulation was performed for two conditions, i.e. without cooling (natural air convection) and air force convection. Then the calculation results of heat removal in the generator cooling are correlated by actual cooling using hydrogen. The applied boundary conditions consist of a heat source generator based on losses (windage, core and rotational) and cooling system. Assuming an average ambient temperature of the power plant at $35^{\circ} \mathrm{C}$, the temperature distribution on the generators of finite element simulation results without cooling or natural convection to all three condition can be shown in Fig. Temperature distribution represented in a 2-dimensions form for call now generator segment and it can be seen that no heat concentration or hotspot exists for both conditions. Every segment receives generators are relatively the same temperature flow (evenly).
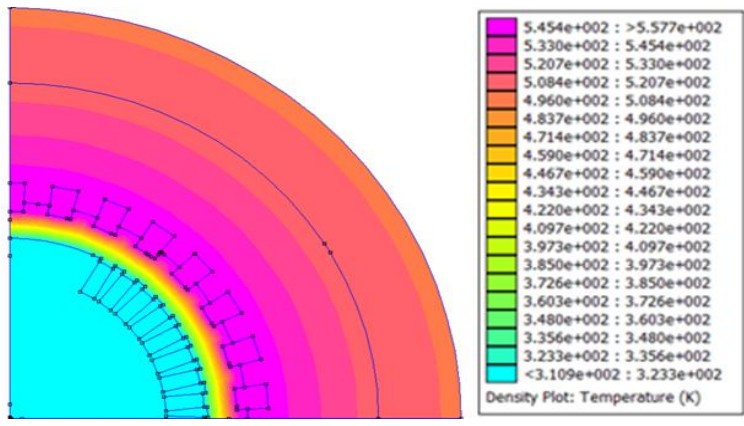

(a)
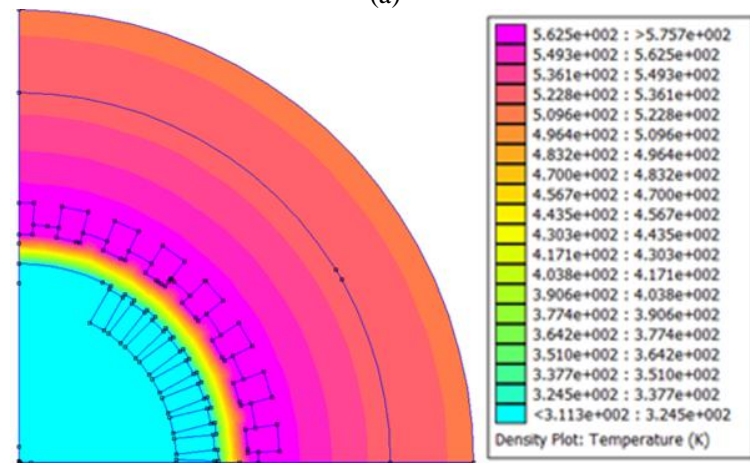

(b)
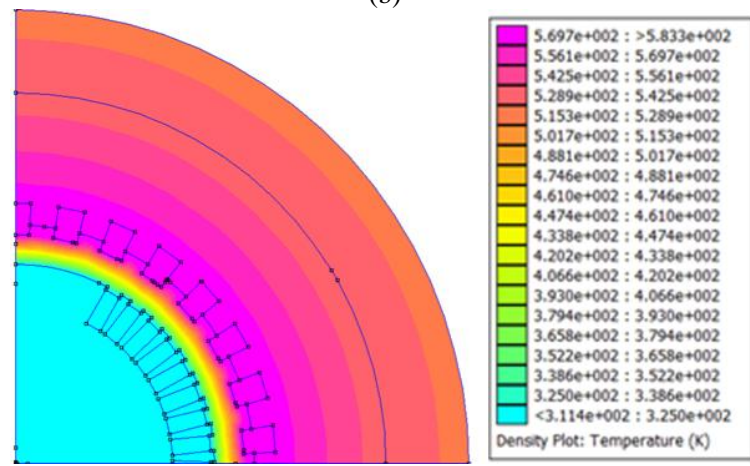

(c)

Fig. 5. Temperature distribution of generator with natural air convection for (a) Existing condition, (b) 5\% Uprating and (c) $7 \%$ Uprating.

The results of thermal simulation results using air cooling system is used as input for the analysis of heat removal using actual hydrogen cooling system. Based on Table III, the approximate relative heat removal using hydrogen cooling is 3.10 bar which has a cooling capacity of as much as four times better when compared by air cooling. Therefore, if the calculations are carried out according to data from the thermal simulation results, the ratio of heat removal in the stator winding for all the three cases using some type of cooling system can be shown in Table IV. To validate the numerical simulations using actual conditions, the temperature of the components in particular generator coil is then compared by actual conditions in accordance by generator operating data on existing conditions and maximum power. Based on the operating data from the control room of the power plant, there are 6 thermocouple sensors mounted on 6 locations of the coil / winding, where the average winding temperature has a value $1.47{ }^{\circ} \mathrm{C}$ or 
$0.42 \%$ lower than the coil temperature simulation results on the same conditions or existing. However, the maximum temperature that occurs in the sixth position of the coil (Coil 1) is $11.7{ }^{\circ} \mathrm{C}$ or $3.33 \%$ higher than the simulation results. In order to eliminate the risk of insulation failure, the maximum actual temperature on the existing condition is used as a reference for existing coil temperature, and the estimation of the raising temperature associated with $5 \%$ and $7 \%$ uprating with the same cooling conditions at hydrogen pressure of 3.10 bar is based on the simulation results by the maximum error of $\pm 3: 33 \%$. Therefore it can be concluded that the raising temperature on winding due to the $5 \%$ and $7 \%$ uprating is $29.9{ }^{\circ} \mathrm{C}$ and $31.1{ }^{\circ} \mathrm{C}$ respectively by the largest error $\pm 3: 33 \%$.

TABLE V: THE APPROXIMATE HEAT REMOVAL FOR EXISTING AND UPRATING CONDITIONS

\begin{tabular}{lllll}
\hline Condition & Parameter & Existing & $\begin{array}{l}5 \% \\
\text { Uprating }\end{array}$ & $\begin{array}{l}7 \% \\
\text { Uprating }\end{array}$ \\
\hline $\begin{array}{l}\text { Natural air } \\
\text { cooled }\end{array}$ & T. Coil, ${ }^{\circ} \mathrm{C}$ & 284.7 & 302.7 & 310.3 \\
Force air cooled & T. Coil, ${ }^{\circ} \mathrm{C}$ & 233.1 & 247.4 & 253.4 \\
& Heat rem., ${ }^{\circ} \mathrm{C}$ & 51.6 & 55.3 & 56.9 \\
Hydrogen cooled & T. Coil, ${ }^{\circ} \mathrm{C}$ & 129.9 & 136.8 & 139.6 \\
2.07 bar & Heat rem., ${ }^{\circ} \mathrm{C}$ & 154.8 & 165.9 & 170.7 \\
Hydrogen cooled & T. Coil, ${ }^{\circ} \mathrm{C}$ & 78.3 & 81.5 & 82.7 \\
3.10 bar & Heat rem., ${ }^{\circ} \mathrm{C}$ & 479.4 & 494.2 & 500.6 \\
\hline
\end{tabular}

\section{CONCLUSION}

Thermal analysis using finite element methods shows temperature distribution in generator accurately and detail in every segment of the generator. Based on the simulation results, there was no indication of heat concentration point or hotspot on the generator. The increasing temperatures on winding due to the $5 \%$ and $7 \%$ uprating were respectively $29.9^{\circ} \mathrm{C}$ and $31.1^{\circ} \mathrm{C}$ by the largest error $\pm 3.33 \%$. Thermal studies using a computational fluid dynamic (CFD) technique is recommended for further study in an attempt to obtain more accurate results, therefore the interaction between the cooling fluids and heat sources on the generator can be analyzed dynamically.

\section{REFERENCES}

[1] Optimized Maintenance of Generator Rotors, Electric Power Research Institute (EPRI), Palo Alto, CA, 1004951, 2004.

[2] D. Azizi and A. Gholami, "Optimization of semiconductive coating and groundwall insulation layers in stator slot of HV generator," Electrical Power and Energy Systems, vol. 57, pp. 384-391, 2014.

[3] P. Irasari, H. S. Alam, and M. Kasim, "Thermal analysis on radial flux permanent magnet generator (PMG) using finite element method," The Journal for Technology and Science, vol. 22, pp. 102-109, 2011.

[4] J. A. Malumbres, M. Satrustegui, I. Elosegui, J. C. Ramos, and M. M. Iturralde, "Analysis of relevant aspects of thermal and hydraulic modeling of electric machines: Application in an open self ventilated machine," Applied Thermal Engineering, vol. 75, pp. 277-288, 2015.

[5] Z. Zhanga, S. M. Muyeenb, A. Al-Durrab, R. Nilssena, and A. Nysveena, "Multiphysics 3D modelling of ironless permanent magnet generators," Energy Procedia, vol. 53, pp. 34-43, 2014.
[6] J. S. Park, S. Park, K. M. Kim, B. S. Choi, and H. H. Cho, "Effect of the thermal insulation on generator and micro gas turbine system," Energy, vol. 59, pp. 581-589, 2013.

[7] B. Ganji, M. Heidarian, and J. Faiz, "Modeling and analysis of switched reluctance generator using finite element method," Ain Shams Eng J, 2014.

[8] S. B. Andersen, I. F. Santos, and A. Fuerst, "Multi-physics modeling of large ring motor for mining industry-Combining electromagnetism, fluid mechanics, mass and heat transfer in engineering design," Applied Mathematical Modelling, 2014.

[9] Y. Alexandrova, R. S. Semken, and J. Pyrhönen, "Permanent magnet synchronous generator design solution for large direct-drive wind turbines: Thermal behavior of the LC DD-PMSG," Applied Thermal Engineering, vol. 65, pp. 554-563, 2014

[10] M. Polikarpova, P. Lindh, C. Gerada, M. Rilla, V. Naumanen, and J. Pyrhonen, "Thermal effects of stator potting in an axial-flux permanent magnet synchronous generator," Applied Thermal Engineering, vol. 75, pp. 421-429, 2015.

[11] K. Ohyama, M. Naguib, F. Nashed, K. Aso, H. Fujii, and H. Uehara, "Design using finite element analysis of a switched reluctance motor for electric vehicle," JPE, vol. 6, no. 2, pp. 163-171, 2014.

[12] Z. X. Chen et al., "Thermal analysis of solid rotor in PMSM used for EV," in Proc. the Vehicle Power and Propulsion Conference, 2009, pp. 1637-1642.

[13] A. Boglietti, A. Cavagnino, D. Staton, M. Shanel, M. Mueller, and C. Mejuto, "Evolution and modern approaches for thermal analysis of electrical machines," IEEE Transactions on Industrial Electronics. vol. 56, no. 3, pp. 871-82, 2009.

[14] G. Mahalingam and A. Keyhani, Technical Report, Department of Electrical Engineering, The Ohio State University, 2000.

[15] I. Boldea and A. N. Syed, The Induction Machine Handbook, Electronic Edition, CRC Press LLC, 2002.

[16] F. Kreith, Principles of Heat Transfer, 3rd ed. Harper \& Row Publisher, Inc, 1973.

[17] S. S. Rao, The Finite Element Method in Engineering, Elsevier Science and Technology Books, 2004, p. 3.

[18] D. V. Hutton, Fundamental of Finite Element Analysis, The Mc Graw Hill Company, 2004, p. 4.

[19] D. Meeker, Finite Element Method Magnetics Version 4.2: User's Manual, 2009.

[20] American Society of Power Engineers. (2015).Basic AC Electrical Generator. [Online]. Available: http://www.asope.org/pdfs/AC_Electrical_Generators_ASOPE.pdf

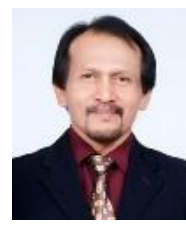

Demi Soetraprawata received his B.S. degree in physic from Nasional University, Indonesia in 1996 and M.S. degree in instrumentation and control from Institut Teknologi Bandung, Indonesia in 2014. He worked as a researcher at Indonesian Institute of Sciences (LIPI) from 1983 until now. His research areas are renewable energy, instrumentation and control

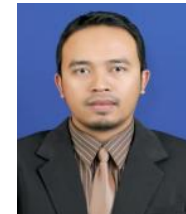

Hilman Syaeful Alam received his B.S. degree in mechanical engineering from Jenderal Achmad Yani University, Indonesia in 2003 and M.S. degree in mechanical engineering from Institut Teknologi Bandung, Indonesia in 2010, He worked as a researcher at Indonesian Institute of Sciences (LIPI) from 2006 unti now. His research areas are renewable energy, energy conversion, engineering design, intelligent material \& structures, instrumentation \& control, finite element and computational mechanics.

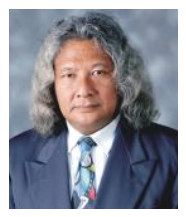

Imam Djunaedi received his B.S. degree in mechanical engineering from Institut Teknologi Bandung, Indonesia in 1984. He had been research as a Ph.D research student at Curtin University of Technology, Australia from 1993 to 1996 . He worked as a researcher at Indonesian Institute of Sciences (LIPI) from 1986 until now. His research areas are renewable energy, optimization, mechatronics, therma engineering and power plant. 